\title{
Is It Complicated? Validity of Personality Interactions for Predicting Performance
}

Jacob C. Bradburn

Michigan State University

Ann Marie Ryan

Michigan State University

Anthony Boyce

Aon Hewitt

Tamera McKinniss

$A C T$, Inc.

Jason Way

$A C T$, Inc.

Follow this and additional works at: https://scholarworks.bgsu.edu/pad

Part of the Human Resources Management Commons, Industrial and Organizational Psychology Commons, and the Other Psychology Commons

How does access to this work benefit you? Let us know!

\section{Recommended Citation}

Bradburn, Jacob C.; Ryan, Ann Marie; Boyce, Anthony; McKinniss, Tamera; and Way, Jason (2020) "Is It Complicated? Validity of Personality Interactions for Predicting Performance," Personnel Assessment and Decisions: Number 6 : Iss. 3 , Article 4. DOI: https://doi.org/10.25035/pad.2020.03.004

Available at: https://scholarworks.bgsu.edu/pad/vol6/iss3/4

This Main Article is brought to you for free and open access by the Journals at ScholarWorks@BGSU. It has been accepted for inclusion in Personnel Assessment and Decisions by an authorized editor of ScholarWorks@BGSU. 


\title{
Is It Complicated? Validity of Personality Interactions for Predicting Performance
}

\author{
Jacob C. Bradburn' ', Ann Marie Ryan', Anthony Boyce ${ }^{2}$, Tamera \\ McKinniss ${ }^{3}$, and Jason Way ${ }^{3}$
}

\author{
1. Michigan State University \\ 2. Aon Hewitt \\ 3. ACT, Inc.
}

\begin{abstract}
KEYWORDS
assessment, employee selection, interaction, personality
\end{abstract}

\begin{abstract}
Research on personality within the organizational sciences and for employee selection typically focuses on main effects, as opposed to interactive effects between personality variables. Large, multi-organizational datasets involving two different measures of personality were examined to test theoretically driven trait by trait interactions in predicting job performance. Interactive effects of Agreeableness and Conscientiousness, Agreeableness and Extraversion, Extraversion and Conscientiousness, and Emotional Stability and Conscientiousness were hypothesized as predicting overall job performance. However, these hypothesized effects were generally not supported. Implications for personality assessment are discussed.
\end{abstract}

Personality research in the organizational sciences generally focuses on the main effects of personality variables on an outcome such as job performance or job satisfaction, as opposed to interactive effects between personality variables. An individual is a constellation of all his or her traits and the configuration of these traits may impact the manifestation of each other. The goal of this study was to examine the incremental contribution of personality trait interactions in the prediction of job performance above main effects utilizing two large, multiorganizational datasets of employees.

\section{Personality in Employee Selection}

Some consensus has emerged on the five factor model (FFM) as a valid and dominant model of personality (see Digman, 1990 for a review), and this model has experienced considerable use since the 1990s (Barrick et al., 2001). The FFM consists of Extraversion, Neuroticism (reverse coded as Emotional Stability), Agreeableness, Conscientiousness, and Openness to Experience. Meta-analyses have shown personality to be predictive of performance for a wide range of jobs (e.g. Barrick \& Mount, 1991; Barrick et al., 2001) and over long periods of time (Judge et al., 1999). Personality has also been associated with a number of other valued workplace outcomes such as job satisfaction (Judge et al., 2002), organizational citizenship behaviors (Chiaburu et al., 2017), and performance motivation (Judge \& Ilies, 2002), and has been used extensively for employee selection (Rothstein \& Goffin, 2006).

\section{Personality Variable Interactions and Job Performance}

Though the usefulness of personality main effects in the prediction of organizationally relevant outcomes is difficult to dispute, the utility of personality trait interactions has not been thoroughly considered in the prediction of job performance. For instance, Barrick and colleagues (2001) found over 200 studies to include in their meta-analysis on the relationship between personality main effects and performance, although there are only a handful of studies exploring interactive effects on performance. A survey of the existing literature reveals inconsistent support. Table 1 summarizes the limited research on personality trait interactions and performance for interactions explored in the present manuscript. This past research suffers from a number of limitations, including limited sample size (e.g. $N=78$ : Sample 2, Warr, 2005; $N=122$ : Judge \& Erez, 2007) that can lead to underpowered studies and testing interactions within a single occupation (e.g. Grant, 2013; Yost, 2014) or organization (e.g. Burke \& Witt, 2002; 2004). These limitations may explain the divergent findings present within this literature.

\footnotetext{
Corresponding author:

Jacob C. Bradburn

316 Physics Road, East Lansing, MI 48825

Email: Bradbu17@msu.edu
} 
TABLE 1.

Past Research on Personality Trait Interaction Effects on Performance

\begin{tabular}{|c|c|c|c|c|}
\hline Interaction & Study & Sample & $N$ & Finding \\
\hline \multirow[t]{8}{*}{$\begin{array}{l}\text { Conscientiousness } \times \\
\text { Agreeableness }\end{array}$} & $\begin{array}{l}\text { Witt, Burke, Barrick, \& } \\
\text { Mount, } 2002\end{array}$ & $\begin{array}{l}\text { Seven samples (various } \\
\text { occupations \& organizations) }\end{array}$ & $146-371$ & $\begin{array}{l}\text { Significant in five of } \\
\text { seven samples }\end{array}$ \\
\hline & $\begin{array}{l}\text { Guay, Oh, Choi, Mitchell, } \\
\text { Mount, \& Shin, } 2013\end{array}$ & Bank employees & 113 & $\begin{array}{l}\text { Significant (task } \\
\text { performance \& OCBs) }\end{array}$ \\
\hline & Burke \& Witt, 2004 & Clerical employees & 338 & ns \\
\hline & Foster \& Macan, 2006 & Meta-analytic sample & & $\begin{array}{l}\text { ns or unexpected } \\
\text { direction }\end{array}$ \\
\hline & Judge \& Erez, 2007 & $\begin{array}{l}\text { Health and fitness center } \\
\text { employees }\end{array}$ & 122 & ns \\
\hline & $\begin{array}{l}\text { Warr, Bartram \& Martin, } \\
2005\end{array}$ & Salespersons (three samples) & $78-119$ & ns \\
\hline & Taylor, 2008 & $\begin{array}{l}\text { Managers (various organizations } \\
\& \text { industries) }\end{array}$ & 680 & ns \\
\hline & Yost, 2014 & $\begin{array}{l}\text { Grocery store managerial } \\
\text { employees }\end{array}$ & 619 & ns \\
\hline \multirow[t]{3}{*}{$\begin{array}{l}\text { Conscientiousness } \times \\
\text { Extraversion }\end{array}$} & Witt, 2002 & $\begin{array}{l}\text { Various positions (three } \\
\text { samples) }\end{array}$ & $130-195$ & Significant \\
\hline & Yost, 2014 & $\begin{array}{l}\text { Grocery store managerial } \\
\text { employees }\end{array}$ & 619 & ns \\
\hline & Warr et al., 2005 & Salespersons (three samples) & $78-119$ & ns \\
\hline \multirow{4}{*}{$\begin{array}{l}\text { Conscientiousness } \times \\
\text { Emotional Stability }\end{array}$} & Teng \& Liu, 2014 & Nursing staff & 313 & Significant \\
\hline & Dunn, 2014 & Undergraduate students & 205 & ns \\
\hline & Yost, 2014 & $\begin{array}{l}\text { Grocery store managerial } \\
\text { employees }\end{array}$ & 619 & ns \\
\hline & Warr et al., 2005 & Salespersons (three samples) & 78-119 & ns \\
\hline \multirow{2}{*}{$\begin{array}{l}\text { Extraversion } \times \\
\text { Agreeableness }\end{array}$} & Grant, 2013 & Call center employees & 340 & ns \\
\hline & Yost, 2014 & $\begin{array}{l}\text { Grocery store managerial } \\
\text { employees }\end{array}$ & 619 & ns \\
\hline
\end{tabular}

Note. $\mathrm{ns}=$ nonsignificant

Taking potential interactive effects into account may enable employers to more effectively select potential employees. Due to the comparatively limited research in the area of personality interactions predicting job performance and potential value in supportive results, as well as frequent conflicting findings and limitations of previous research, further research in this area is warranted. Although there are many trait by trait interactions that could be examined in relation to job performance, we focus on four specific interactions with strong theoretical rationale: Agreeableness and Conscientiousness, Agreeableness and Extraversion, Extraversion and Conscientiousness, and Emotional Stability and Conscientiousness.

Conscientiousness $\times$ Agreeableness. Effective job performance overall requires both completing tasks effectively and interacting effectively with others (e.g. Borman \& Motowidlo, 1997). Individuals who are highly conscientious but lack social skills, as evidenced through low Agreeableness, may not experience the full benefits of being a conscientious worker (Witt et al., 2002). For example, "without the tendency to be cooperative, considerate, and trusting (i.e. low in agreeableness), conscientiousness will likely add little to performance" (p. 165). Alternatively, individuals who display high Agreeableness may function effectively interpersonally, but if low in Conscientiousness may lack the detail orientation and diligence to complete tasks effectively. Effective overall job performance requires both, and having both high Agreeableness and Conscientiousness should interact to facilitate higher performance than if one was lacking. Based on this rationale, we hypothesize that: 
Hypothesis 1: Agreeableness will moderate the relationship between Conscientiousness and overall job performance, such that there will be a stronger positive relationship between Conscientiousness and overall job performance among individuals with higher levels of Agreeableness.

Some past research has not found support for the usefulness of this interaction in predicting job performance. Foster and Macan (2006) utilized a meta-analytic approach with over 100 datasets and failed to find consistent interactive effects between Conscientiousness and Agreeableness. Burke and Witt (2004) found that the interaction of Conscientiousness and Agreeableness did not significantly predict high-maintenance employee behaviors. Other published (e.g. Judge \& Erez, 2007; Warr, et al., 2005) and unpublished (e.g. Taylor, 2008: Yost, 2014) research has also failed to find an interactive effect between Conscientiousness and Agreeableness in predicting job performance.

However, other research has found more promising results for this interaction. Witt and colleagues (2002) found that the interaction of Agreeableness and Conscientiousness was predictive of supervisor rated performance above main effects in five of seven samples from different organizations. In this study, among individuals who were high in Conscientiousness, those with high Agreeableness as well received higher performance ratings. Guay and colleagues (2013) replicated these general findings in a small sample of South Korean bank employees by demonstrating a significant interaction of Agreeableness and Conscientiousness in predicting task performance as well as organizational citizenship behaviors.

Again, these mixed results in the literature may be a function of power limitations in utilizing small samples and the homogeneous samples used. Our study seeks to bring some clarity to these mixed findings by utilizing larger and more occupationally diverse samples.

Extraversion $\times$ Agreeableness. The limited past research into the interaction of Agreeableness and Extraversion in predicting job performance is interesting, as these FFM traits both represent socially oriented traits in the FFM framework (McCrae \& Costa, 1989). McCrae and Costa (1989) suggest that, "These two appear to determine directly the amount of social stimulation preferred and prevailing quality of social interaction" (p. 586). If Extraversion determines desire for social interaction and Agreeableness determines interaction quality, a person high in Agreeableness and high in Extraversion may have more positive interactions than an individual low in Agreeableness and high in Extraversion, leading to higher job performance. In contrast, an individual who has high Extraversion and low Agreeableness may see limited benefits from their Extraversion, as their disagreeable nature may lead to low quality interactions. Thus, we hypothesize that:
Hypothesis 2: Agreeableness will moderate the relationship between Extraversion and overall job performance, such that there will be a stronger positive relationship between Extraversion and overall job performance among individuals with higher levels of Agreeableness.

In a study utilizing call center employees, Grant (2013) included the interaction of Agreeableness and Extraversion in a regression with a large number of other variables and did not find it to be predictive of objective sales revenue. Yost (2014) also failed to find an interactive effect between Extraversion and Agreeableness in predicting leader effectiveness. This previous research suffers from a number of limitations, such as relying on relatively small samples and individuals within one specific organization. Based on the limitations of these previous studies, firm conclusions regarding this moderating effect are difficult to draw, and thus we test this effect within our study.

Conscientiousness $\times$ Extraversion. Having a high degree of Extraversion with a low degree of Conscientiousness may lead to an individual being disruptive to the workflow of an organization through nonorganizationally relevant social interaction with peers. However, a highly extraverted and conscientious individual may harness and focus this energy and social need towards building effective customer and coworker relationships. Though a highly extraverted and conscientiousness individual may still desire a high degree of social interaction, their conscientious nature may allow them to redirect these social tendencies toward more productive sources where individuals with low Conscientiousness may not. Having high Extraversion without high Conscientiousness may dampen the positive effects of this trait. Based on this rationale, we hypothesize that:

\section{Hypothesis 3: Conscientiousness will moderate the relationship between Extraversion and overall job performance, such that there will be a stronger posi- tive relationship between Extraversion and overall job performance among individuals with higher levels of Conscientiousness.}

Past research into the interaction of Conscientiousness and Extraversion for predicting performance has found mixed results. Research by Witt (2002) found a significant interaction of Extraversion and Conscientiousness in predicting performance in three independent samples utilizing different personality inventories. Those employees with high Conscientiousness exhibited a positive relationship between Extraversion and performance, where the relationship for those low in Conscientiousness was negative. Yost (2014), however, did not find interactive effects in predicting leadership effectiveness. Warr and colleagues (2005) also did not find significant interactive effects between Con- 
scientiousness and Extraversion for predicting objective sales performance in three samples of salespersons.

Conscientiousness $\times$ Emotional Stability. As main effects, both Conscientiousness and Emotional Stability have consistently predicted job performance (e.g. Barrick et al., 2001). However, a low degree of Emotional Stability may hinder the positive attributes associated with high Conscientiousness. A highly conscientious individual may thoroughly check his or her work, where a highly neurotic and highly conscientious individual may obsess over word choice or sentence structure to the point where performance suffers. A highly conscientious individual may plan for the future, where a highly neurotic and conscientious individual may, due to anxiety and rigidness, be unable to adapt effectively if these plans need to change. Without a high degree of Emotional Stability in tandem with high Conscientiousness, the benefits of this trait for performance may not be realized. Based on this rationale, we hypothesize that:

Hypothesis 4: Emotional Stability will moderate the relationship between Conscientiousness and overall job performance, such that there will be a stronger positive relationship between Conscientiousness and overall job performance among individuals with higher levels of Emotional Stability.

Past research into this interaction has found mixed results. Yost (2014) failed to find a significant interaction between Conscientiousness and Emotional Stability in the prediction of cognitively oriented leader effectiveness. Warr and colleagues (2005) also failed to find interactive effects. Teng and Liu (2014) found that the interaction of Conscientiousness and Emotional Stability was predictive of overall customer service performance for Taiwanese nurses. The authors also found differing directions for the relationship of Conscientiousness and customer service performance facets depending on the level of Emotional Stability for nurses.

\section{METHOD}

\section{Sample}

Secondary data were provided by two organizations that administer personality assessments to external clients. Sample 1 consisted of 8,125 employees from five companies, with 427 self-declared job titles represented. ${ }^{1} N$ per occupation ranged from 1 to 521 , and $N$ per company ranged from 370 to 2,818 . $^{2}$

Sample 2 consisted of 1,256 individuals representing 119 occupations from seven companies, though a large number came from one healthcare system. Occupations were self-selected from a list of O*NET job categories. $N$ per occupation ranged from 1 to 195 , and $N$ per company from 1 to 996.

\section{Measures}

Personality. Individuals in Sample 1 were administered the Adaptive Employee Personality Test (ADEPT-15 (B), a computer adaptive personality test that utilized item response theory-based ideal-point modeling (see Stark et al., 2006; Tay et al., 2011 for more information on ideal-point models). This assessment also utilized a forcedchoice, multi-unidimensional, pairwise preference model in which individuals taking the assessment were presented with a choice to endorse two statements and must choose one (see Stark et al., 2005, 2012, for more information on multi-unidimensional pairwise preference models). This assessment consisted of 15 personality dimensions (see Table 2) and has been demonstrated to have construct validity vis-à-vis other measures of personality as well as criterion-related validity (Boyce et al., 2015) consistent with meta-analytic estimates for personality in general (Barrick \& Mount, 1991). Individual item response theory-based theta estimates for personality variables from the adaptive assessment were utilized in Sample 1.

Individuals in Sample 2 were administered the WorkKeys ${ }^{\circledR}$ Talent assessment, a 165-item Internet-administered personality assessment based on the five-factor model of personality and emotional intelligence literature. Items were presented on a six-point Likert scale ranging from strongly disagree to strongly agree (ACT, 2016). The assessment consisted of 12 scales (see Table 3). Scale scores were calculated by summing item scores within each scale. The scales varied in terms of the number of items.

The ADEPT-15 is an aspect-based (e.g., DeYoung et al., 2007) personality assessment, and the WorkKeys Talent assessment is a facet-based personality assessment; however, scales from both assessments map onto the FFM traits and were aggregated together up to the FFM level for these analyses (see Table 4 for relationships between ADEPT-15 and WorkKeys Talent variables and FFM variables) based on information available in each respective assessment's technical documentation (see Table 4).

Job performance. Supervisory job performance ratings were utilized as the criterion. Within Sample 1, individuals had job performance ratings unique to the organization, and in one organization different rating measures for managers and staff. Overall job performance ratings were computed by combining individual items into a unit-weighted composite within organization, and seperately for managers and

\footnotetext{
1 For a subset of these data $(\mathrm{N}=1,436)$ job titles were not available and the general job category was utilized (e.g. finance, IT specialist, etc) in this count, representing 20 job titles across this subsample.

2 For Sample 1, individuals who took the assessment in under $5 \mathrm{~min}$ utes were excluded prior to analyses due to inattentive responding. On the criterion side, performance data collected for individuals were not retained if there was no variance in ratings (e.g. receiving top marks on all measures), if the supervisor had low confidence in the ratings, or if the supervisor had limited experience with the employee.
} 
TABLE 2.

ADEPT-15 ${ }^{\oplus}$ Dimensions

\begin{tabular}{|l|l|l|}
\hline Dimension & Definition & Test-retest reliability \\
\hline Drive & proactive and persistent & .61 \\
\hline Structure & planful, detail oriented, and rule conscious & .70 \\
\hline Conceptual & conceptual and intellectually curious & .71 \\
\hline Flexibility & flexible, adaptable, and open minded & .68 \\
\hline Mastery & learning oriented and improvement oriented & .55 \\
\hline Ambition & ambitious and goal-directed & .62 \\
\hline Power & controlling, directive, and motivated to lead & .56 \\
\hline Assertiveness & assertive, directive, and motivated to lead & .69 \\
\hline Liveliness & outgoing, energetic, and socially confident & .71 \\
\hline Composure & composed, calm, and relaxed & .73 \\
\hline Positivity & happy, optimistic, and resilient & .70 \\
\hline Awareness & reflective and self-aware & .44 \\
\hline Cooperativeness & cooperative and trusting & .66 \\
\hline Sensitivity & compassionate, caring, and understanding & .66 \\
\hline Humility & modest and genuine & .57 \\
\hline
\end{tabular}

Note. Adapted from Boyce, Conway \& Caputo, 2015. Test-retest reliability represents a 2-week delay between administrations and is reported from previous research.

TABLE 3.

WorkKeys ${ }^{\oplus}$ Talent Dimensions (ACT, 2016)

\begin{tabular}{|l|l|l|}
\hline Dimension & Definition & Reliability (alpha) \\
\hline Carefulness & think and plan carefully & .81 \\
\hline Discipline & $\begin{array}{l}\text { responsible, dependable, and follow through with tasks without becoming distracted or } \\
\text { bored }\end{array}$ & .87 \\
\hline Order & neat and well-organized & .85 \\
\hline Stability & maintain composure and rationality in situations of actual or perceived stress & .86 \\
\hline Optimism & having a positive outlook and confidence of actual or perceived outcomes & .83 \\
\hline Cooperation & likable and cordial in interpersonal situations & .83 \\
\hline Goodwill & forgiving and believe others are well-intentioned & .82 \\
\hline Sociability & enjoy being in other people's company and work with others & .89 \\
\hline Influence & $\begin{array}{l}\text { impact and dominate social situations by speaking without hesitation and often } \\
\text { becoming a group leader }\end{array}$ & .86 \\
\hline Striving & have high aspiration levels and work hard to achieve goals & .86 \\
\hline Creativity & be imaginative and think “outside the box" & .85 \\
\hline Savvy & $\begin{array}{l}\text { read other people's motives, understand office politics, and anticipate the needs and } \\
\text { intentions of others }\end{array}$ & .83 \\
\hline
\end{tabular}

Note. Reliability information reported from previous research (ACT, 2016). 
staff for the one organization where these ratings differed. Alphas for the overall performance composite ranged from .94 to .96 . These overall job performance ratings for Sample 1 were standardized using a $Z$-score transformation in order to facilitate comparability across organizations and positions.

Sample 2 utilized uniform performance rating scales across companies and occupations tapping core (two scales), compliance (two scales), adaptive (three scales), and interpersonal (three scales) aspects of performance. Ratings on each subscale were combined to create an overall performance composite. Three subscales, two relating to change and one relating to interpersonal performance, were not included in the overall performance composite because only a subset of individuals was administered these measures. Within this dataset, the alpha for the overall performance composite was .93. Note that the overall job performance composite was standardized in Sample 1 and unstandardized in Sample 2.

\section{Analyses}

Because individuals in the dataset were nested within occupations and companies, ICC(1) values were calculated for both to determine if multilevel analyses would be nec- essary. ICC(1) values were relatively high for both company and job (see Table 5), suggesting multilevel analyses as appropriate. Additionally, within each sample, overall performance was regressed onto each of the FFM variables utilizing both an OLS regression and three-level multilevel regression with random intercepts for each occupation within companies and model fit was compared. For each of these comparisons in both samples, the three-level random intercept model fit significantly better than a one-level model based on the significance of the likelihood ratio test ${ }^{3}$ (see Table 6 for results of comparisons). Fit for a three-level random intercept model was also compared to fit for a three-level random intercept and slope model in a similar manner. The random intercept and slope model did not fit significantly better based on likelihood ratio tests in any comparison (see Table 7 for results), suggesting adding random slopes did not increase model fit. Thus, three-level random intercept models were used for analyses.

Quadratic terms were included for each of the personality factors within moderator analyses as controls, as recommended by Cortina (1993). Main effects within samples were grand mean centered prior to analyses and the creation of the quadratic terms. Interactive terms were created by multiplying grand means centered main effects.

\section{TABLE 4.}

Relationship Between ADEPT- $15^{\circledR}$ and WorkKeys ${ }^{\oplus}$ Talent Dimensions and Five Factor Model Factors

\begin{tabular}{|l|l|l|}
\hline \multicolumn{1}{|c|}{ Five Factor model factor } & \multicolumn{1}{c|}{ ADEPT-15 facets } & \multicolumn{1}{c|}{ WorkKeys Talent facets } \\
\hline Conscientiousness & Structure, drive & Carefulness, discipline, order \\
\hline Extraversion & Assertiveness, liveliness & Sociability, influence, striving \\
\hline Agreeableness & Sensitivity, cooperation & Cooperation, goodwill \\
\hline Emotional Stability & Composure, positivity & Stability, optimism \\
\hline Openness to Experience & Conceptual, flexibility & Creativity \\
\hline
\end{tabular}

TABLE 5. ICC(1) Values for Personality and Performance, for Occupation and Company and Combined

\begin{tabular}{lcccccccc}
\hline & \multicolumn{4}{c}{ Sample 1 } & & \multicolumn{3}{c}{ Sample 2 } \\
\cline { 2 - 3 } \cline { 7 - 8 } & Company & Occupation & $\begin{array}{c}\text { Company \& } \\
\text { occupation }\end{array}$ & & Company & Occupation & $\begin{array}{c}\text { Company \& } \\
\text { occupation }\end{array}$ \\
\hline Conscientiousness & .01 & .02 & .03 & & .08 & .04 & .12 \\
Extraversion & .01 & .02 & .02 & & .13 & .07 & .21 \\
Agreeableness & .01 & .01 & .02 & & .04 & .07 & .11 \\
Emotional Stability & .04 & .01 & .04 & & .08 & .04 & .13 \\
Overall performance & .00 & .09 & .09 & & .09 & .03 & .12 \\
\hline
\end{tabular}

3 This test compares model fit to determine if one model fits the data significantly better than another based on the log-likelihood fit information for each model, differences in degrees of freedom, and a chi-squared distribution. More information regarding this test can be found in Bliese (2016). 


\section{RESULTS}

Intercorrelations for variables are available for Samples 1 and 2 in Tables 8 and 9, respectively. Hypotheses 1 through 4 were tested utilizing three-level moderated linear regression with random intercepts by occupation within company. See Tables 10 through 17 for the results of these analyses, including models with only main effects, adding in quadratic terms, and the full moderation model. Agreeableness did not significantly moderate the relationship between Conscientiousness and job performance in Sample $1(\beta=.00, t(7693)=-.27, p=.78)$. This moderation was significant in Sample $2(\beta=-.10, t(1077)=-2.01, p=.04)$. However, this interaction was in the opposite direction than predicted as the relationship was stronger for those with low Agreeableness (see Figure 1), thus Hypothesis 1 was

\section{TABLE 6.}

Model Fit Comparing OLS Regression to Three-Level Multilevel Regression With Random Intercepts for Overall Performance

\begin{tabular}{lll}
\hline Factor & Sample 1 & Sample 2 \\
\hline Conscientiousness & $519.45^{* * *}$ & $54.81 * * *$ \\
Extraversion & $516.60 * * *$ & $63.77 * * *$ \\
Agreeableness & $519.14 * * *$ & $60.94 * * *$ \\
Emotional Stability & $520.01 * * *$ & $55.29 * * *$ \\
\hline Note. $* * * p<.01$. Values represent likelihood ratios. Sample 1: \\
Level 1 (Individual) $N=8,125$, Level 2 (Occupation) $N=427$, \\
Level 3 (Company) $N=5$. Sample 2: Level 1 (Individual) $N=$ \\
$1,255-1,256$, Level 2 (Occupation) $N=173$, Level 3 (Company) \\
$N=7$.
\end{tabular}

not supported. Agreeableness did not significantly moderate the relationship between Extraversion and overall job performance in Sample $1(\beta=.01, t(7693)=.51, p=.61)$ or Sample $2(\beta=.06, t(1077)=1.41, p=.16)$; thus, Hypothesis 2 was not supported. ${ }^{4}$ Conscientiousness did not significantly moderate the relationship between Extraversion and job performance in Sample $1(\beta=-.01, t(7693)=-.59, p=.55)$ or Sample $2(\beta=-.03, t(1077)=-.84, p=.40)$, thus Hypothesis 3 was not supported. Emotional Stability did not significantly moderate the relationship between Conscientiousness and job performance in Sample $1(\beta=-.02, t(7693)=$ $-1.42, p=.15)$ or Sample $2(\beta=-.07, t(1077)=-1.76, p=$ $.08)$. Based on these results, Hypothesis 4 was not supported.

\section{TABLE 7.}

Model Fit Comparing Three-Level Multilevel Regression With Random Intercepts to Three-Level Multilevel Regression With Random Intercept and Slopes for Overall Performance

\begin{tabular}{lcc}
\hline Variable & Sample 1 & Sample 2 \\
\hline Conscientiousness & .00 & .47 \\
Extraversion & .00 & 8.04 \\
Agreeableness & $.70 \dagger$ & $.10 \dagger$ \\
Emotional Stability & .00 & .47 \\
\hline
\end{tabular}

Note. Values represent likelihood ratios. Sample 1: Level 1 (Individual) $N=8,125$, Level 2 (Occupation) $N=427$, Level 3 (Company) $N=5$. Sample 2: Level 1 (Individual) $N=1,255-$ 1,256, Level 2 (Occupation) $N=173$, Level 3 (Company) $N=7$. $\uparrow$ Utilizes R's general purpose optimization routine as opposed to default due to non-convergence with the latter, as suggested by Bliese, 2016.

TABLE 8.

Intercorrelations of Personality and Performance, Sample 1

\begin{tabular}{lllllll}
\hline Sample & $M$ & $S D$ & 1 & 2 & 3 & 4 \\
\hline 1. Conscientiousness & .35 & .64 & & & & \\
2. Extraversion & .25 & .67 & .15 & & & \\
3. Agreeableness & .45 & .68 & .13 & .25 & \\
4. Emotional Stability & .49 & .67 & .22 & .18 & .28 & \\
5. Overall performance & .00 & 1.00 & .08 & .01 & .02 & .05 \\
\hline
\end{tabular}

Note. $N=8,125$. All correlations greater than .03 are significant $p<.01$. Overall performance was standardized within Sample 1 .

TABLE 9.

Intercorrelations of Personality and Performance, Sample 2

\begin{tabular}{lcccccc}
\hline Sample & $M$ & $S D$ & 1 & 2 & 3 & 4 \\
\hline 1. Conscientiousness & 196.60 & 21.25 & & & & \\
2. Extraversion & 177.49 & 26.98 & .48 & & & \\
3. Agreeableness & 128.79 & 12.93 & .61 & .51 & & \\
4. Emotional Stability & 120.17 & 17.31 & .56 & .58 & .69 & .18 \\
5. Overall performance & 109.80 & 19.40 & .20 & .12 & .17 \\
\hline
\end{tabular}

Note. $N=1,255-1,256$. All correlations greater than .03 are significant $p<.01$. 


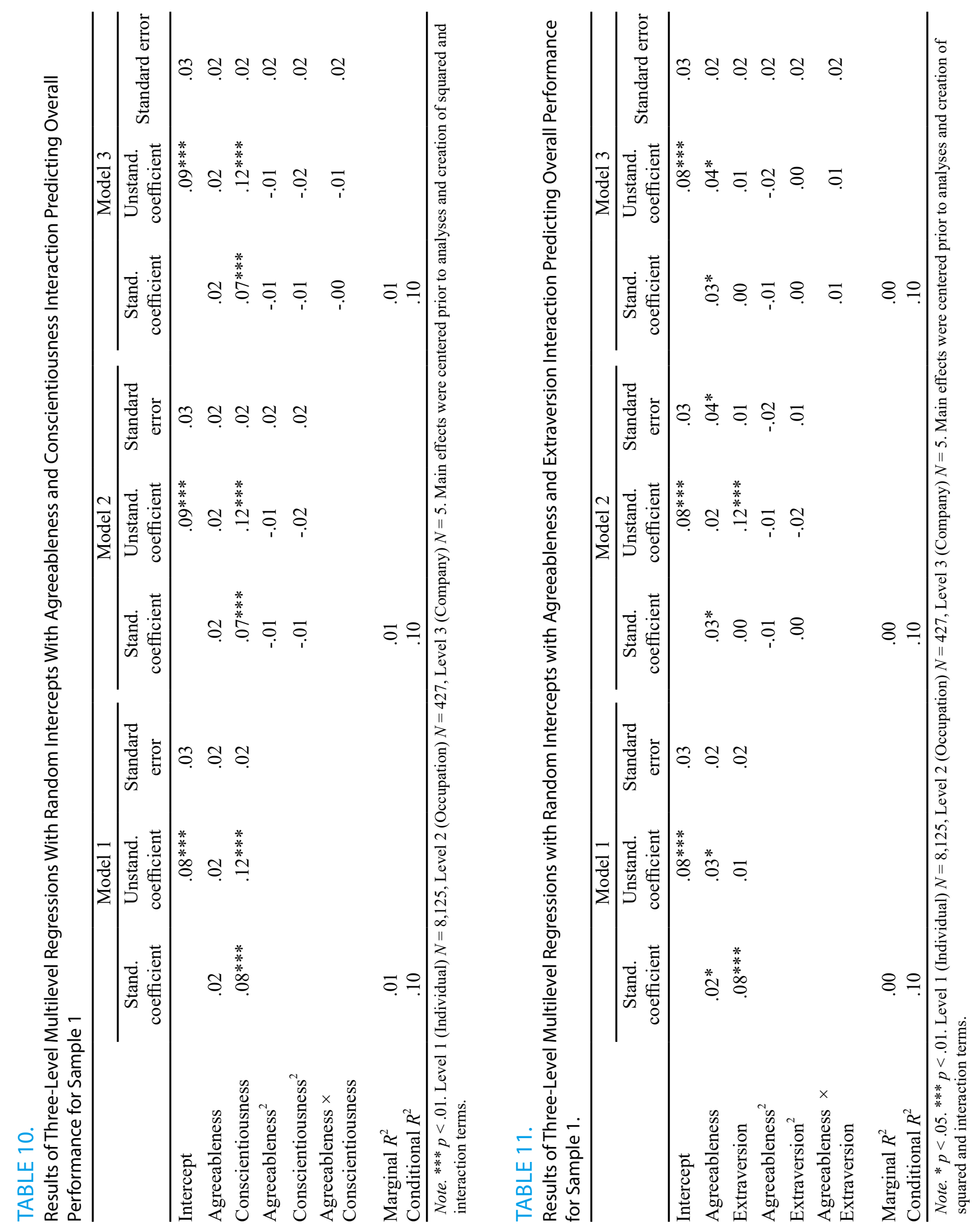




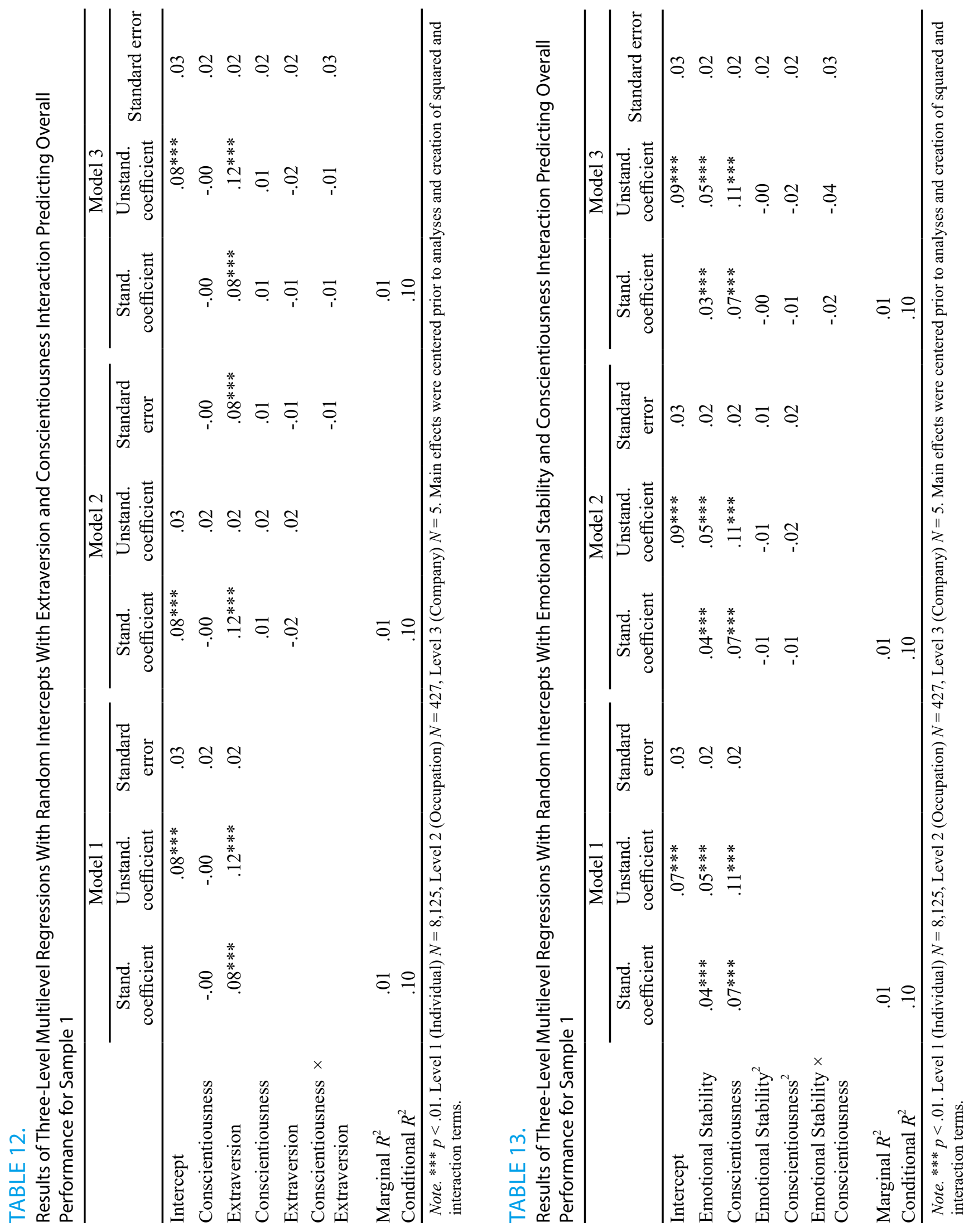




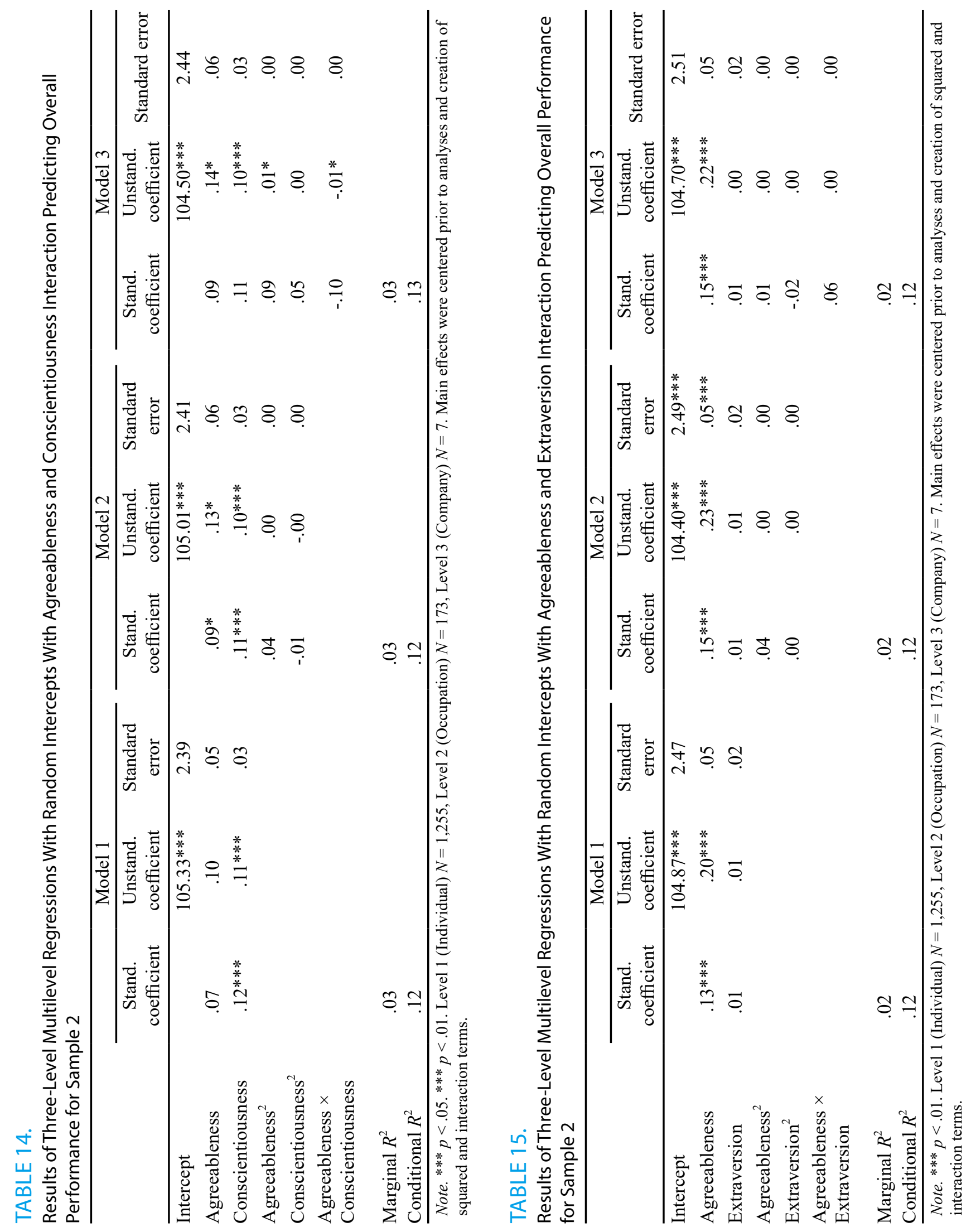




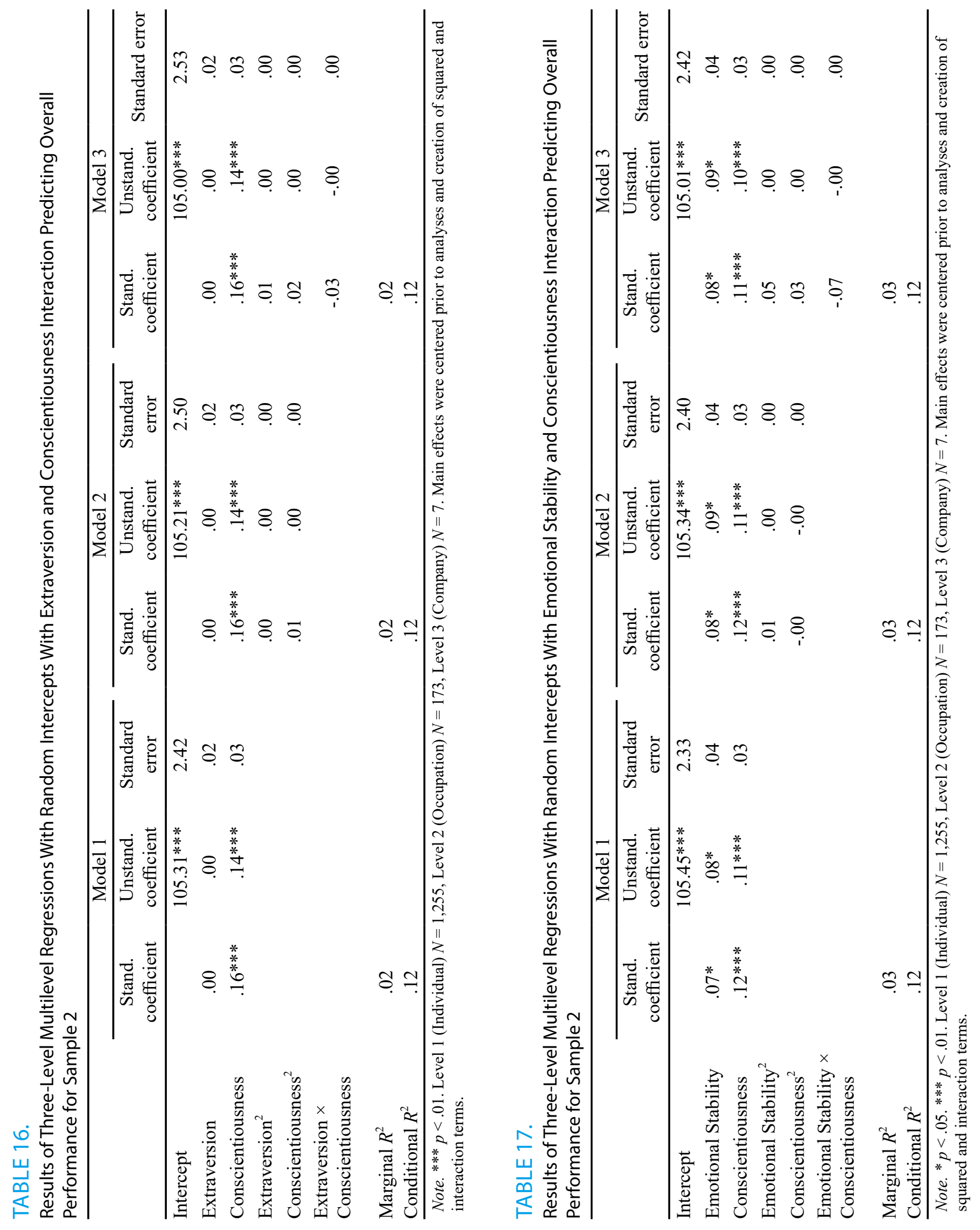


FIGURE 1.

Agreeableness Moderating Relationship Between Conscientiousness and Overall Job Performance in Sample 2

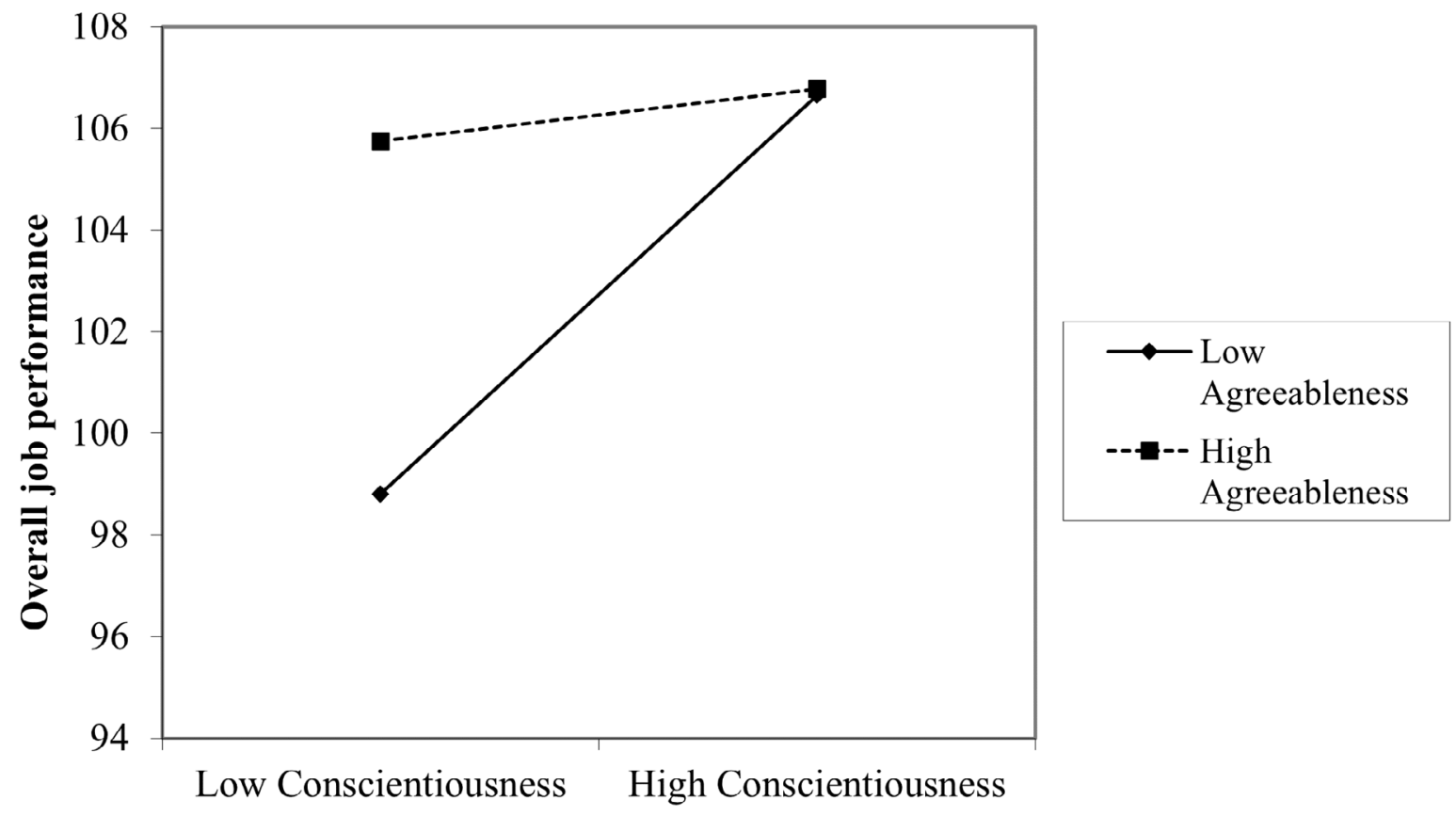

\section{DISCUSSION}

The purpose of the present study was to evaluate the potential utility of personality trait interactions in the prediction of performance. To address the limitations of much of the previous research in this area, this study used two large multi-organizational and occupationally diverse samples. Significant main effects were found that were in line with past research (e.g. significant effects of Conscientiousness and Emotional Stability in predicting performance; Barrick et al., 2001). However, the results of this study do not suggest the specific personality trait interactions tested can aid in the prediction of job performance, despite theoretical rationale for such effects. These results are in line with previous research that found little support for the use of these personality variable interactions in predicting performance (e.g. Warr et al., 2005). Theoretically, these results suggest that though these traits are collectively a part of the FFM of personality, their relationships with overall job performance are independent. In terms of practical implications, the results of this study do not suggest value in considering these personality interactions in selection contexts.

Although a significant moderating effect was found for Agreeableness on the relationship between Conscientiousness and overall job performance in Sample 2, this effect was in the opposite direction than predicted. Conscientiousness was more strongly related to overall job performance for those low in Agreeableness than those high in Agree- ableness. A post-hoc explanation could be that Agreeableness is a highly salient characteristic that may influence supervisor ratings of job performance. However, a high degree of Conscientiousness may function in a compensatory way for those low in Agreeableness as a supervisor may look beyond disagreeableness and see the quality of work being produced through detail oriented, thorough, and dutiful tendencies. In this way, high Conscientiousness may compensate for low Agreeableness in some work settings. It should be noted that given the large number of interactions tested, finding moderation in the opposite direction than predicted, and the lack of support for this interaction across samples, this significant effect may be a type 1 error (i.e. false positive).

Psychology has had a long history of reliance on small sample sizes within research and issues with underpowered studies (Maxwell, 2004) and utilizing samples of questionable representativeness (e.g. Henrich et al., 2010). Based

4 Past research has demonstrated that matching personality variables to narrower and more theoretically driven performance outcomes than overall performance can enhance validity (e.g. Hogan \& Roberts, 1996). As Agreeableness and Extraversion are both socially oriented traits, supplemental analyses were also conducted following this rationale examining the interaction of Agreeableness and Extraversion in predicting interpersonal performance, as opposed to overall performance, for Sample 1 and 2 separately. No significant relationship was found between this interaction and interpersonal performance in either sample, mirroring results found for overall job performance. 
upon this study utilizing larger and more occupationally diverse samples, ${ }^{5}$ more firm support can be drawn that, in general, the personality interactions examined do not significantly contribute to the prediction of overall job performance. Though the results of this study suggest a lack of usefulness for these personality trait interactions in predicting performance, future research is warranted to explore why Conscientiousness may be more predictive of overall performance for low Agreeableness individuals, the replicability of this interaction, to examine additional outcomes (e.g. more narrowly tailored performance criteria) and to consider possible interactive effects between other personality and individual difference variables in relation to job performance.

As with any research, this study has limitations that may warrant caution in the generalization and interpretation of results. Although both measures used in this study were carefully developed, these measures were originally designed to measure personality variables at the facet or aspect level. Approximation for FFM variables were created by combining these aspects or facets, as opposed to measuring these FFM variables at the factor level. Also, low reliability for interactions is a persistent limitation in the study of moderating effects in psychological science (e.g. Aguinis et al., 2011).

Within this study, the usefulness of the personality variable interactions studied in predicting performance was limited. However, this does not negate the potential usefulness of personality scales in hiring contexts or potential value from other trait by trait interactions. Despite these generally unsupportive results, future research on this topic may still have potential value in clarifying the practical value of interactive relationships between personality variables.

\section{REFERENCES}

ACT. (2016). About the WorkKeys Talent Assessment. lowa City: ACT, Inc.

Aguinis, H, Gottfredson, R. K., \& Wright, T. A. (2011). Best-practice recommendations for estimating interaction effects using meta-analysis. Journal of Organizational Behavior, 32(8), 1033-1043.

Barrick, M. R. \& Mount, M. K. (1991). The Big Five personality dimensions and job performance: A meta-analysis. Personnel Psychology, 44(1), 1-26. doi: 10.1111/j.1744-6570.1991. tb00688.x

5 Although the relatively high degree of occupational heterogeneity within this sample can be considered an advantage of the present study, it could also be a limitation. It may be the case that the hypothesized interactions may exist within some occupations but not others, and the occupational heterogeneity within the samples utilized may obscure interactions within this subset of occupations.
Barrick, M. R., Mount, M. K., \& Judge, T. A. (2001). Personality and performance at the beginning of the new millennium: What do we know and where do we go next? International Journal of Selection and Assessment, 9(1/2), 9-30. doi: $10.1111 / 1468-2389.00160$

Bliese, P. D. (2016). Multilevel modeling in R (2.6): A brief introduction to $\mathrm{R}$, the multilevel package and the nlme package. $1-92$.

Borman, W. C., \& Motowidlo, S. J. (1997). Task performance and contextual performance: The meaning for personnel selection research. Human Performance, 10(2), 99-109. doi: 10.1207/s15327043hup1002_3

Boyce, A. S., Conway, J. S., \& Caputo, P. M. (2015). ADEPT-15 technical documentation: Development and validation of Aon Hewitt's Personality Model and Adaptive Employee Personality Test (ADEPT-15). Aon Hewitt.

Burke, L. A. \& Witt, L. A. (2002). Moderators of the Openness to Experience-performance relationship. Journal of Managerial Psychology, 17(8), 712-721. doi: 10.1108/02683940210450501

Burke, L. A. \& Witt, L. A. (2004). Personality and high-maintenance employee behavior. Journal of Business and Psychology, 18(3), 349-363.

Chiaburu, D. S., Oh, I. S., \& Marinova, S. V. (2017). Five-factor model of personality traits and organizational citizenship behavior: Current research and future directions. In P. M. Podsakoff, S. B. Mackenzie, \& N. P. Podsakoff (Ed.), The Oxford handbook of organizational citizenship behavior. Online publication. doi:10.1093/oxfordhb/9780190219000.013.13

Cortina, J. M. (1993). Interaction, nonlinearity, and multicollinearity: Implications for multiple regression. Journal of Management, 19(4), 915-922. doi: 10.1177/014920639301900411

DeYoung, C. G., Quilty, L. C., \& Peterson, J. B. (2007). Between facets and domains: 10 aspects of the Big Five. Journal of Personality and Social Psychology, 93(5), 880-896. doi: 10.1037/0022-3514.93.5.880

Digman, J. M. (1990). Personality structure: Emergence of the five-factor model. Annual Review of Psychology, 41, 417440

Dunn, A. M. (2014). Re-examining the positive Conscientiousness-performance relationship: The role of Neuroticism and stress. Unpublished Master's Thesis

Foster, J. \& Macan, T. (2006, May). The use of interactions between personality variables to predict performance. Paper presented at the 21st Annual Conference of the Society for Industrial and Organizational Psychology in Dallas, Texas.

Grant, A. M. (2013). Rethinking the extraverted sales ideal: The ambivert advantage. Psychological Science, 24(6), 10241030. doi: $10.1177 / 0956797612463706$

Guay, R. P., Oh, I. S., Choi, D., Mitchell, M. S., Mount, M. K., \& Shin, K. (2013). The interactive effect of Conscientiousness and Agreeableness on job performance dimensions in South Korea. International Journal of Selection and Assessment, 21(2), 233-238. doi: 10.1111/ijsa.12033

Henrich, J., Heine, S. J., \& Norenzayan, A. (2010). The weirdest people in the world?. Behavioral and brain sciences, 33(2-3), 61-83.

Hogan, J. \& Roberts, B. W. (1996). Issues and non-issues in the fidelity-bandwidth trade-off. Journal of Organiza- 
tional Behavior, 17(6), 627-637. doi:10.1002/(SICI)10991379(199611)17:6<627::AID-JOB2828>3.0.CO;2-F

Judge, T. A. \& Erez, A. (2007). Interaction and intersection: The constellation of Emotional Stability and Extraversion in predicting performance. Personnel Psychology, 60(3), 573-596. doi: 10.1111/j.1744-6570.2007.00084.x

Judge, T. A., Heller, D., \& Mount, M. K. (2002). Five-factor model of personality and job satisfaction: A meta-analysis. Journal of Applied Psychology, 87(3), 530-541. doi: 10.1037//00219010.87.3.530

Judge, T. A., Higgins, C. A., Thoresen, C. J., \& Barrick, M. R. (1999). The Big Five personality traits, general mental ability, and career success across the life span. Personnel Psychology, 52(3), 621-652. doi: 10.1111/j.1744-6570.1999.tb00174.x

Judge, T. A. \& Ilies, R. (2002). Relationship of personality on performance motivation: A meta-analytic review. Journal of Applied Psychology, 87(4), 797-807. doi: 10.1037//00219010.87.4.797.

Maxwell, S. E. (2004). The persistence of underpowered studies in psychological research: Causes, consequences, and remedies. Psychological Methods, 9(2), 147-163. doi: 10.1037/1082-989X.9.2.147

McCrae, R. R. \& Costa, P. T. (1989). The structure of interpersonal traits: Wiggin's circumplex and the five-factor model. Journal of Personality and Social Psychology, 56(4), 586-595. doi: 10.1037/0022-3514.56.4.586

Rothstein, M. G., \& Goffin, R. D. (2006). The use of personality measures in personnel selection: What does current research support? Human Resource Management Review, 16(2), 155-180. doi: 10.1016/j.hrmr.2006.03.004

Stark, S., Chernyshenko, O. S., \& Drasgow, F. (2005). An IRT approach to constructing and scoring pairwise preference items involving stimuli on different dimensions: The multi-unidimensional pairwise-preference model. Applied Psychological Measurement, 29(3), 184-203. doi: 10.1177/0146621604273988

Stark, S., Chernyshenko, O. S., Drasgow, F., \& White, L. A. (2012). Adaptive testing with multidimensional pairwise preference items: Improving the efficiency of personality and other noncognitive assessments. Organizational Research Methods, 15(3), 463-487. doi: 10.1177/1094428112444611

Stark, S., Chernyshenko, O. S., Drasgow, F., \&Williams, B. A. (2006). Examining assumptions about item responding in personality assessment: Should ideal point methods be considered for scale development and scoring? Journal of Applied Psychology, 91(1), 25-39. doi: 10.1037/0021-9010.91.1.25

Tay, L., Ali, U. S., Drasgow, F., \& Williams, B. (2011). Fitting IRT models to dichotomous and polytomous data: Assessing the relative model-data fit of ideal point and dominance models. Applied Psychological Measurement, 35(4), 280295. doi: 10.1177/0146621610390674

Taylor, A. M. (2008). The validity of personality trait interactions for the prediction of managerial job performance. Unpublished master's thesis.

Teng, C. I. \& Liu, T. W. (2014). How do personality interactions affect service quality? The perspective of processing efficiency theory. Service Business, 8(2), 375-397. doi: 10.1007/ s11628-013-0200-3
Warr, P., Bartram, D., \& Martin, T. (2005). Personality and sales performance: Situational variation and interactions between traits. International Journal of Selection and Assessment, 13(1), 87-91. doi: 10.1111/j.0965-075x.2005.00302.x

Witt, L. A. (2002). The interactive effects of Extraversion and Conscientiousness on performance. Journal of Management, 28(6), 835-851.

Witt, L. A., Burke, L. A., Barrick, A. R., \& Mount, M. K. (2002). The interactive effects of Conscientiousness and Agreeableness on job performance. Journal of Applied Psychology, 87(1), 164-167. doi: 10.1037//0021-9010.87.1.164

Yost, A. B. (2014). Does taking a more holistic view of personality improve its predictive utility? A comparison multiple regression, fuzzy cluster analysis, and indirect mixture modeling for predicting leadership effectiveness. Unpublished doctoral dissertation.

RECEIVED 08/26/19 ACCEPTED 07/10/20 